\title{
Comparative Studies of Thulium and Erbium-doped Fiber Amplifiers for Dynamic Optical WDM Networks
}

\author{
M A Khamis \\ Baqubah technical institute \\ Middle technical university \\ Baghdad, Iraq \\ mustafaelectronic@gmail.com
}

\author{
K Ennser \\ College of engineering \\ Swansea university \\ Swansea, UK \\ k.ennser@swansea.ac.uk
}

\begin{abstract}
In this study, a two-level laser system model is presented to simulate the dynamic behavior of the thuliumdoped fiber amplifier at $2 \mu \mathrm{m}$ region. Numerical methods are used to investigate the effects of channels drop in thuliumdoped fiber amplifier performance and compare to that in erbium-doped fiber amplifier at $1.55 \mu \mathrm{m}$ region. Our findings revealed that the dynamic performance of a thulium-doped amplifier is smaller than for an erbium-doped fiber amplifier. We propose the use of an optical gain-clamping technique to reduce the effects of power transients in both optical amplifiers due to the channels drop in reconfigurable wavelength division multiplexing system. We show that the optical gain-clamped technique is more efficient when applied to thulium-doped fiber amplifier than erbium-doped fiber amplifier. As a result, the thulium-doped fiber amplifier shows greater stability with a larger broadband to enable high capacity WDM transmission.
\end{abstract}

Keywords-thulium doped fiber amplifier, power excursion, optical gain clamped, numerical method.

\section{INTRODUCTION}

Recent research studies show that the transmission capacity of the conventional fiber is limited to around 100Tbit per second due to the limitation of the incident power. This limitation is caused by the fiber non-linear effects or fiber fuse phenomenon [1]. The demand of increasing the network capacity has motivate the research interest toward essential new approach such as multi-mode or core fiber and space division multiplexing [2,3]. These approaches have currently offered interesting prospects and shown impressive telecom performance. However, most of the studies for enhancing the transmission capacity have been focused toward the conventional fiber transmission at $1.55 \mu \mathrm{m}$ of optical waveband and the amplification of erbium doped fiber amplifiers (EDFAs) [4].

Thulium-doped fiber amplifiers (TDFAs) at $2 \mu \mathrm{m}$ propose the widest gain amplification spectrum of all rare earth amplifiers. TDFA characterizes an attractive way to increase the transmission capacity via shifting away from the current transmission window around $1.55 \mu \mathrm{m}$. In addition, the operating wavelength around $2 \mu \mathrm{m}$ overlaps with a low loss window of a hollow-core photonic bandgap fiber [5,6]. Additionally, TDFAs have been developed for optical telecom, indicating high gain amplification, low noise and broadband spectrum cover about $30 \mathrm{THz}(1700$ $2100 \mathrm{~nm}$ ) of spectrum bandwidth in a single device. This amplification bandwidth is more than two times in that of the EDFA with the same configuration and complexity $[7,8]$.
The large amplification bandwidth of TDFAs can be exploited by using the wavelength division multiplexing (WDM) technology. However, the input power to the amplifier varies with time because of channel dropping or adding in dynamic reconfigurable WDM. This variation causes gain transients in the optical amplification when it reaches the saturation and leads to an increase in power excursion which is referred to the ratio of maximum to minimum power of the surviving channel. The distance of WDM transmission could be restricted due to TDFA dynamics and cause problematic transients in telecom networks [9]. A simple and robust method to reduce the effect of gain dynamic is by clamping the amplification gain via a lasing feedback signal. This technique has been investigated for EDFAs in the C-band region [10], for TDFAs in S-band [11] and for TDFA in $2 \mu \mathrm{m}$ region [12].

In this study, we investigate the dynamic behavior of a TDFA around $2 \mu \mathrm{m}$ for WDM reconfigurable network and compare its dynamic to a EDFA around $1.55 \mu \mathrm{m}$ region. We first present the theoretical model of gain clamping scheme in WDM reconfiguration network for an optical amplifier at two-level system. Then, we investigate and compare the power excursion variation for clamped and unclamped gain amplifier in EDFA and TDFA at $1.55 \mu \mathrm{m}$ and $2 \mu \mathrm{m}$ waveband regions, respectively.

\section{THE GAIN CLAMPED MODEL FOR EDFA/TDFA}

The dynamic model expressed in our model is based in laser point of view at two-level system. In this model, we describe the dynamic behaviour of laser transitions in EDFA and TDFA to investigate the optical gain unclamped and clamped. According to the theoretical model of TDFA [13], the behaviour of thulium doped fiber transitions can be expressed similar to EDFA with two energy levels when pumped at $1.558 \mu \mathrm{m}$. Thus, we can apply this model at both EDFA and TDFA to study the dynamic behavior at add/drop channels of WDM systems. The rate equations of the dynamic model are based on the following equations [12]:

$$
\begin{gathered}
\frac{d N_{2}}{d t}=-\frac{N_{2}}{\tau_{T / E}}-\frac{1}{V}\left[F_{s}(t)\left(G_{s}(t)-1\right)\right] \\
-\frac{1}{V}\left[F_{p}(t)\left(G_{p}(t)-1\right)\right] \\
N_{0}=N_{2}+N_{1}
\end{gathered}
$$

where $\mathrm{N}_{0}$ is the ion concentration of thulium/erbium, $\mathrm{N}_{1}$ and $\mathrm{N}_{2}$ are the concentration of levels ${ }^{3} \mathrm{H}_{6}$ and ${ }^{3} \mathrm{~F}_{4}$, respectively, 
for thulium, ${ }^{4} \mathrm{I}_{15 / 2}$ and ${ }^{4} \mathrm{I}_{13 / 2}$ for erbium. $\mathrm{V}$ is the active volume, $\tau_{\mathrm{T} / \mathrm{E}}$ is the fluorescence time of thulium/erbium, $\mathrm{G}_{\mathrm{s}}$ is the signal gain, and $G_{p}$ is the pump gain, which are given by:

$$
\begin{aligned}
& G_{p}=e^{\Gamma_{p} L\left(\sigma_{e p} N_{2}-\sigma_{a p} N_{1}\right)} \\
& G_{s}=e^{\Gamma_{s} L\left(\sigma_{e s} N_{2}-\sigma_{a s} N_{1}\right)}
\end{aligned}
$$

where $\Gamma_{\mathrm{p}}$ and $\Gamma_{\mathrm{s}}$ are the overlapping factors for the pump and signal, respectively; $\sigma_{\text {ap }}$ and $\sigma_{\text {as }}$ represent the absorption cross-section of the pump and the signal wavelength, and $\sigma_{\mathrm{ep}}$ and $\sigma_{\mathrm{es}}$ represent the emission cross-section of the pump and the signal wavelength. Also, $\mathrm{L}$ is the length of the thulium/erbium-doped fiber and $\mathrm{A}_{\mathrm{eff}}$ is the effective area of the thulium/erbium fiber core. In eq. (1), $F_{s}$ and $F_{p}$ are the laser and the pump flux, respectively. Based on the laser approach, the pump flux is given by (5):

$$
F_{p}(t)=x(t) F_{p, t h}
$$

Note that in our model we set the power factor $\mathrm{x}$ to unity at unclamped gain and greater than unity for clamped gain, which implies that the clamped case has extra pump power to effectively clamp the gain. $F_{p, t h}$ is the pump flux at laser threshold, which is given by (6):

$$
F_{p, t h}=\frac{\frac{N_{2}}{\tau_{T / E}}+\frac{1}{A_{e f f} L} F_{s}\left(G_{s}-1\right)}{\frac{\left(1-G_{p}\right)}{A_{e f f} L}}
$$

The optical gain clamped-TDFA design consists of two couplers, variable attenuator ATT, bandpass filter BPF and the thulium amplifier, which are connected together in a closed-loop configuration as illustrated in Fig. 1. The laser signal builds up in a feedback loop, which forms a laser system.

The laser signal saturates TDFA and fixes a fractional value of the population inversion by adding the feedback signal into (1). Therefore, the rate equations for optical gain clamped-TDFA are as following [13]:

$$
\begin{gathered}
\frac{d N_{2}}{d t}=-\frac{N_{2}}{\tau_{E / T}}-\frac{1}{V}\left[F_{s}(t)\left(G_{s}(t)-1\right)\right] \\
-\frac{1}{V}\left[F_{p}(t)\left(G_{p}(t)-1\right)\right]-\frac{1}{V}\left[F_{L}(t)\left(G_{L}(t)-1\right)\right] \\
\frac{d F_{L}}{d t}=\frac{F_{L}(t)\left(G_{L}(t) \alpha_{L}-1\right)}{T}
\end{gathered}
$$

where $G_{L}$ and $F_{L}$ represent laser gain and flux, respectively, $\alpha_{\mathrm{L}}$ is the optical loss of laser cavity and $\mathrm{T}$ is the round-trip time in the lasing cavity. From the above models, we can see that the add/drop channels are expressed as negative pump power fluctuations due to the decreasing of a thulium inversion by signal photons.

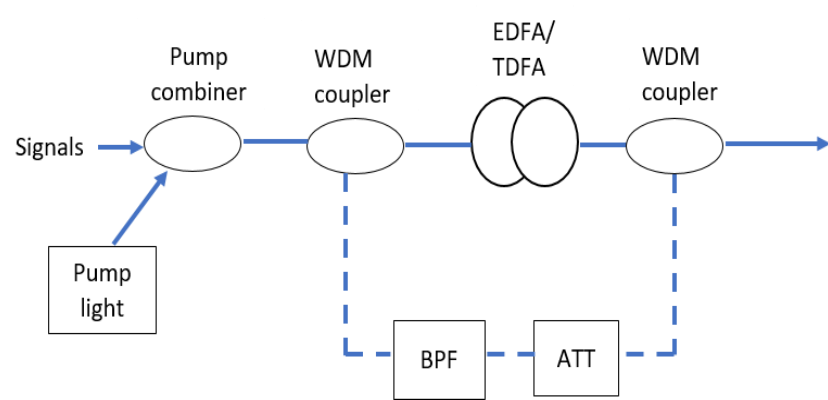

Fig. 1. Thulium/erbium doped-fiber amplifier in ring laser configuration. ATT is variable optical attenuator and BPF is the bandpass filter.

\section{RESULTS AND DISCUSSION}

In this study, we develop a MATLAB program to investigate the dynamic behavior of the EDFA/TDFA. We set the total input power at $-4 \mathrm{dBm}$ for 12 channels and each channel power is $-14.79 \mathrm{dBm}$. To focus on the dynamics, the channels are fixed at $1950 \mathrm{~nm}$ for TDFA and $1540 \mathrm{~nm}$

\begin{tabular}{|c|c|c|}
\hline Symbol & Quantity & Value \\
\hline $\mathrm{N}_{\mathrm{T}}$ & Thulium concentration. & $8.4 \times 10^{25} \mathrm{~m}^{-3}$ \\
\hline$\tau_{\mathrm{T}}$ & Lifetime of level ${ }^{3} \mathrm{H}_{4}$. & $650 \mu \mathrm{s}$ \\
\hline$\lambda_{\mathrm{p}}$ & pump wavelength. & $1570 \mathrm{~nm}$ \\
\hline$\lambda_{s}$ & Signal wavelength. & $1950 \mathrm{~nm}$ \\
\hline$\lambda_{l}$ & Laser wavelength. & $1930 \mathrm{~nm}$ \\
\hline$\sigma_{\mathrm{ap}}$ & $\begin{array}{l}\text { Laser absorption cross section } \\
\text { at pump wavelength } 1570 \mathrm{~nm} \text {. }\end{array}$ & $2.5 \times 10^{-25} \mathrm{~m}^{2}$ \\
\hline$\sigma_{\mathrm{as}}$ & $\begin{array}{l}\text { Laser absorption cross section } \\
\text { at signal wavelength1950nm. }\end{array}$ & 0 \\
\hline$\sigma_{\mathrm{al}}$ & $\begin{array}{l}\text { Laser absorption cross section } \\
\text { at laser wavelength1930nm. }\end{array}$ & 0 \\
\hline$\sigma_{\mathrm{ep}}$ & $\begin{array}{l}\text { Laser emission cross section at } \\
\text { pump wavelength } 1570 \mathrm{~nm} \text {. }\end{array}$ & 0 \\
\hline$\sigma_{\mathrm{es}}$ & $\begin{array}{l}\text { Laser emission cross section at } \\
\text { signal wavelength } 1940 \mathrm{~nm} \text {. }\end{array}$ & $2 \times 10^{-25} \mathrm{~m}^{2}$ \\
\hline$\sigma_{\mathrm{el}}$ & $\begin{array}{l}\text { Laser emission cross section at } \\
\text { laser wavelength } 1930 \mathrm{~nm} \text {. }\end{array}$ & $2.5 \times 10^{-25} \mathrm{~m}^{2}$ \\
\hline A & $\begin{array}{c}\text { Cross sectional area of the } \\
\text { core. }\end{array}$ & $3.01 \times 10^{-11} \mathrm{~m}^{2}$ \\
\hline $\mathrm{L}$ & Fiber length & $12 \mathrm{~m}$ \\
\hline$\Gamma_{\mathrm{p}}$ & $\begin{array}{l}\text { Overlapping factor of the } \\
\text { pump wavelength }\end{array}$ & 0.5 \\
\hline$\Gamma_{\mathrm{s}}$ & $\begin{array}{l}\text { Overlapping factor of the } \\
\text { signal wavelength }\end{array}$ & 0.43 \\
\hline
\end{tabular}
for EDFA. The total power is varied according to the number of dropped channels. In this case, the amplifier gain is assumed flat to focus on the dynamics. The typical parameters of our proposed model are shown in Table I and II for TDFA and EDFA, respectively.

TABLE I. TDFA PARAMETER VALUES [12] 
TABLE II. EDFA PARAMETER VALUES [14]

\begin{tabular}{|c|c|c|}
\hline Symbol & Quantity & Value \\
\hline $\mathrm{N}_{\mathrm{T}}$ & Erbium concentration. & $15 \times 10^{23} \mathrm{~m}^{-3}$ \\
\hline$\tau_{\mathrm{E}}$ & Lifetime of level ${ }^{3} \mathrm{I}_{13 / 2}$ & $0.008 \mathrm{~s}$ \\
\hline$\lambda_{\mathrm{p}}$ & pump wavelength. & $980 \mathrm{~nm}$ \\
\hline$\lambda_{s}$ & Signal wavelength. & $1540 \mathrm{~nm}$ \\
\hline$\lambda_{l}$ & Laser wavelength. & $1530 \mathrm{~nm}$ \\
\hline$\sigma_{\mathrm{ap}}$ & $\begin{array}{l}\text { Laser absorption cross section } \\
\text { at pump wavelength } 980 \mathrm{~nm} \text {. }\end{array}$ & $4 \times 10^{-25} \mathrm{~m}^{2}$ \\
\hline$\sigma_{\mathrm{as}}$ & $\begin{array}{l}\text { Laser absorption cross section } \\
\text { at signal wavelength } 1540 \mathrm{~nm} \text {. }\end{array}$ & $3.5 \times 10^{-25} \mathrm{~m}^{2}$ \\
\hline$\sigma_{\mathrm{al}}$ & $\begin{array}{l}\text { Laser absorption cross section } \\
\text { at laser wavelength } 1530 \mathrm{~nm} \text {. }\end{array}$ & $5 \times 10^{-25} \mathrm{~m}^{2}$ \\
\hline$\sigma_{\mathrm{ep}}$ & $\begin{array}{l}\text { Laser emission cross section at } \\
\text { pump wavelength } 980 \mathrm{~nm} \text {. }\end{array}$ & 0 \\
\hline$\sigma_{\mathrm{es}}$ & $\begin{array}{l}\text { Laser emission cross section at } \\
\text { signal wavelength } 1540 \mathrm{~nm} \text {. }\end{array}$ & $5 \times 10^{-25} \mathrm{~m}^{2}$ \\
\hline$\sigma_{\mathrm{el}}$ & $\begin{array}{l}\text { Laser emission cross section at } \\
\text { laser wavelength } 1530 \mathrm{~nm} \text {. }\end{array}$ & $4 \times 10^{-25} \mathrm{~m}^{2}$ \\
\hline A & $\begin{array}{l}\text { Cross sectional area of the } \\
\text { core. }\end{array}$ & $3.01 \times 10^{-11} \mathrm{~m}^{2}$ \\
\hline $\mathrm{L}$ & Fiber length & $20 \mathrm{~m}$ \\
\hline$\Gamma_{\mathrm{p}}$ & $\begin{array}{l}\text { overlapping factor of the pump } \\
\text { wavelength }\end{array}$ & 0.7 \\
\hline$\Gamma_{\mathrm{s}}$ & $\begin{array}{l}\text { overlapping factor of the signal } \\
\text { wavelength }\end{array}$ & 0.5 \\
\hline
\end{tabular}

First, we study the dynamic behaviour of EDFA and TDFA in case of unclamped gain amplifier. We fix the gain of both amplifier at 20dB. Fig. 2 and 3 show the calculated power excursion in EDFA and TDFA, respectively when 6, 8, 10 and 11 channels are dropped. The value of power excursion in TDFA is smaller than EDFA for all cases due to different characteristics of thulium fiber parameters. The required thulium-doped fiber length is shorter due to high thulium ions concentration. It is clearly notice that the dynamic performance of TDFA is better than in EDFA and this characteristic is important in realizing WDM systems with greater stability and long-haul WDM transmission systems.

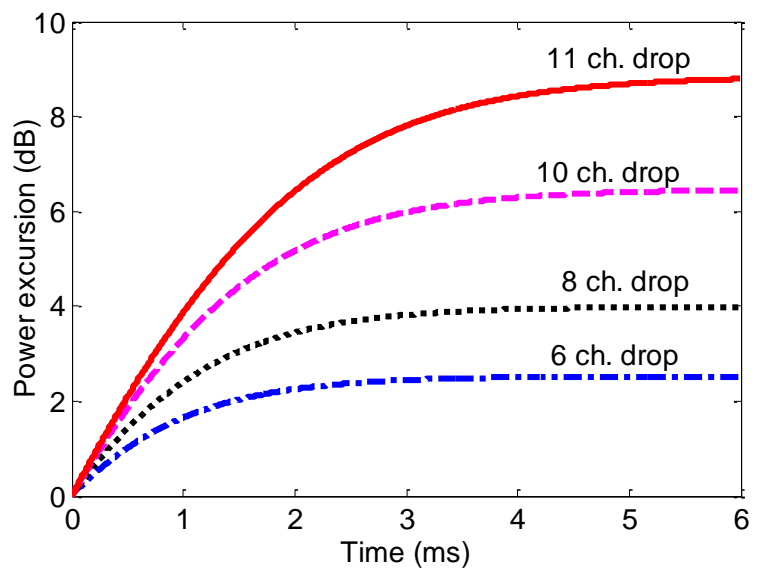

Fig. 2. The calculated output power excursions of surviving channels when $6,8,10$ und 11 of input channels are dropped at unclamped EDFA.

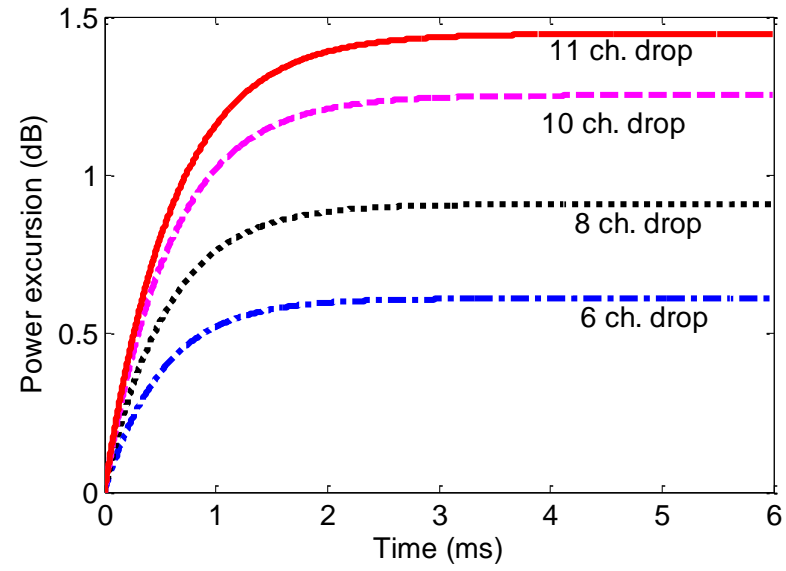

Fig. 3. The calculated output power excursions of surviving channels when $6,8,10$ und 11 of input channels are dropped at unclamed TDFA.

In the second investigation, we study the transient responses of the gain-clamped in EDFA and TDFA. Fig. 4 and 5 illustrate the obtained power excursion in EDFA and TDFA, respectively when 11 channels are dropped. Due to high thulium ions concentration, the OGC-TDFA stabilizes quicker. A short feedback loop length (laser cavity) offers fast transient recovery time because of short photon cavity lifetime as previously demonstrated for erbium doped waveguide amplifier (EDWA) [15]. Additionally, the value of spectral hole burning SHB in EDFA at room temperature is larger than four times of the TDFA [16]. These characteristics make the optical gain clamped technique more efficient when applied to TDFA.

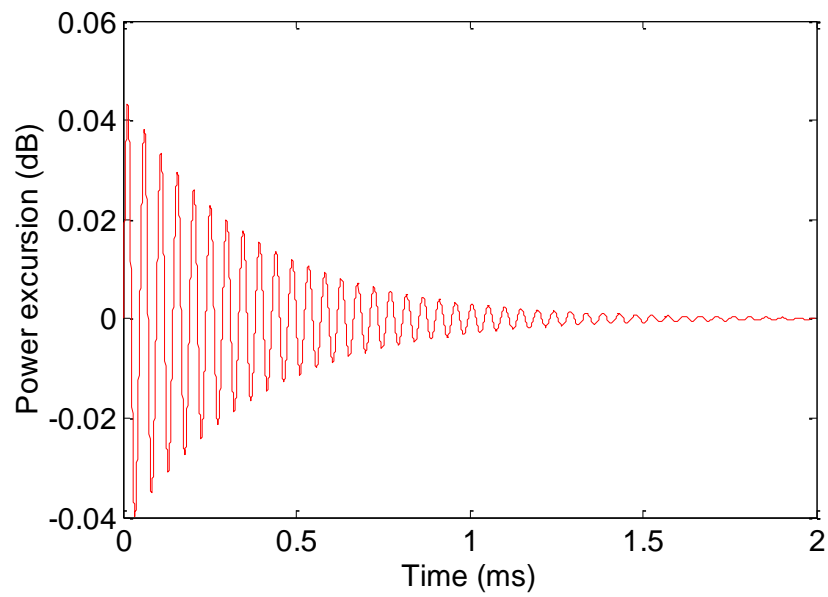

Fig. 4. The calculated output power excursions of surviving channels when 11 of input channels are dropped at clamped EDFA. 


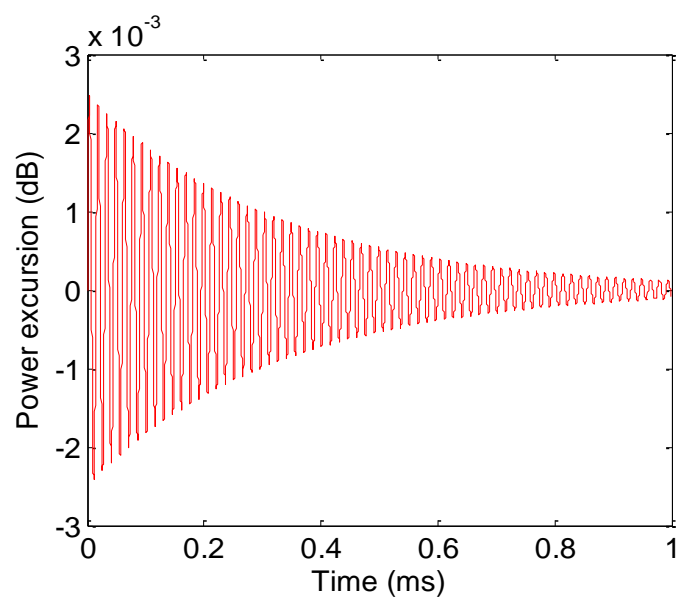

Fig. 5. The calculated output power excursions of surviving channels when 11 of input channels are dropped at clamped TDFA.

\section{CONCLUSION}

In summary, we have investigated the benefits of gainclamped TDFA in the $2 \mu \mathrm{m}$ region and compared to that in EDFA in the $1.55 \mu \mathrm{m}$. The amplifier dynamic model is based on a two-level laser system and the rate equation were solved numerically. Amplification gain and surviving channel power variation have been studied in 12 WDM channels system when the channels are dropped at the TDFA and EDFA.

It can be clearly observed that the value of power excursion in TDFA is several times smaller than EDFA for all cases due to different characteristics of thulium fiber parameters. The effects of power transients due to channel reconfigurations are significantly reduced by a feedback laser signal. As a conclusion, optical gain-clamping is an effective technique to eliminate power excursions due to the dynamic behavior of TDFA for optical WDM transmission system in the $2 \mu \mathrm{m}$ region.

\section{REFERENCES}

[1] R-J. Essiambre, G. Foschini, P. Winzer, and G. Kramer "Capacity limits of fiber-optic communication systems," Proc. OFC/NFOEC, OThL1, 2009.

[2] S. Randel, R. Ryf, A. Sierra, P. J. Winzer, A. H. Gnauck, C. A. Bolle, R.-J. Essiambre, D. W. Peckham, A. McCurdy, and R. Lingle, Jr., " $6 \times 56-\mathrm{Gb} / \mathrm{s}$ mode-division multiplexed transmission over $33-\mathrm{km}$ fewmode fiber enabled by 6×6 MIMO equalization,” Opt. Exp. vol. 19, pp. 16697-16707, 2011.

[3] V. Sleiffer, Y. Jung, V. Veljanovski ...... R. Winfield, A. Ellis, and H. De Waardt, "73.7 Tb/s (96X3×256-Gb/s) mode-divisionmultiplexed DP-16QAM transmission with inline MM-EDFA," in ECOC (2012), paper Th.3.C.4.

[4] T. Sakamoto, T. Mori, T. Yamamoto, and S. Tomita, "Differential mode delay managed transmission line for WDM-MIMO system using multi-step index fiber," J. Lightw. Technol., vol. 30, no. 17, pp. 2783-2787, 2012.

[5] P.J. Roberts, F. Couny, H. Sabert, B.J. Mangan, D.P. Williams, L. Farr, M.W. Mason, A. Tomlinson, T.A. Birks, J.C. Knight, P.St.J.
Russell, Ultimate low loss of hollow-core photonic crystal fibres, Opt. Exp. Vol. 13, pp. 236-244, 2005.

[6] N.Mac SuibhneZ.LiB.Baeuerle, J.Zhao, WDM transmission at $2 \mu \mathrm{m}$ over low-loss hollow core photonic bandgap fiber, in: Optical Fiber Communication Conference/ National Fiber Optic Engineers Conference 2013, OSA Technical Digest (online) (OSA, 2013), paper OW1I.6

[7] Z. Li, S.U. Alam, J.M.O. Daniel, P.C. Shardlow, D. Jain, N. Simakov, A.M. Heidt, Y. Jung, J.K. Sahu, W.A. Clarkson, D.J. Richardson, 90 $\mathrm{nm}$ gain extension towards $1.7 \mu \mathrm{m}$ for diode-pumped silica-based thulium-doped fiber amplifiers, in: European Conference on Optical Communication (ECOC), 2014, pp. 1-3.

[8] Z. LiuZ.Li, Y.Chen, $52.6 \mathrm{Gbit} / \mathrm{s}$ single-channel directly-modulated optical transmitter for $2 \mu \mathrm{m}$ spectral region, in: Optical Fiber Communication Conference, OSA, 2015, paper Th1E.6.

[9] M. Karasek, A. Bononi, L.A. Rusch, M. Menif, Gain stabilization in gain clamped EDFA cascades fed by burst-mode packet traffic, J. Ligth. Technol. vol. 18, pp. 308-313, 2000.

[10] M. Zannin, K. Ennser, S. Taccheo, On the benefits of optical gainclamped amplification in optical burst switching networks, J. Light. Technol. 27 (2009) 5475-5482.

[11] J. Kim, S.S.-H. Yam, M.E. Marhic, Y. Akasaka, Modeling gain dynamics of thulium doped fiber amplifiers, IEEE Photonics Technol. Lett. 17 (2005) 998-1000.

[12] M. A. Khamis, K. Ennser, "Enhancement on the generation of amplified spontaneous emission in thulium-doped silica fiber at 2 $\mu \mathrm{m}$," Optics communications. 384 (2017) 89-92.

[13] M. A. Khamis, K. Ennser, Theoretical model of a thulium-doped fiber amplifier pumped at $1570 \mathrm{~nm}$ and $793 \mathrm{~nm}$ in the presence of cross relaxation, J. Light. Technol. vol. 34, pp. 5675, 2016.

[14] C. R. Giles and E Desurvire "Modeling Erbium-Doped Fiber Amplifiers", J. Light. Technol. vol. 9, pp. 271, 1991.

[15] K. Ennser, Optical gain-clamped erbium-doped waveguide amplifier and its applications, International Microwave \& Optoelectronics ConfInvited Paper, 2007.

[16] F. Roy, D. Bayart, C. Heerdt, A. L. Sauza, P. Baniel, "Spectral hole burning measurement in the thulium-doped fiber amplifier, in: Optical Amplifier and Their Application, OSA Technical Digest Series, paper OWB3. 